\title{
COMMENTARY
}

\section{Benefits and problems of chrome tanning in leather processing: Approach a greener technology in leather industry}

\author{
Kazi Madina Maraz \\ Polymer Composite Laboratory, Institute of Radiation and Polymer Technology, Bangladesh Atomic Energy Commission, Dhaka 1000, \\ Bangladesh
}

\section{Check for updates}

Correspondence to: Kazi Madina Maraz, Polymer Composite Laboratory, Institute of Radiation and Polymer Technology, Bangladesh Atomic Energy Commission, Dhaka, 1000, Bangladesh Email: madina.du.ira@gmail.com

Received: June 16, 2021;

Accepted: September 28, 2021;

Published: October 4, 2021.

Citation: Maraz KM. Benefits and problems of chrome tanning in leather processing: Approach a greener technology in leather industry. Mater Eng Res, 2021, 3(1): 156-164.

https://doi.org/10.25082/MER.2021.01.004

Copyright: () 2021 Kazi Madina Maraz. This is an open access article distributed under the terms of the Creative Commons Attribution License, which permits unrestricted use, distribution, and reproduction in any medium, provided the original author and source are credited.

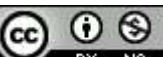

\begin{abstract}
Tanning is the process of converting the raw skin and hides from different animals into a sustainable and manageable material called leather. Leather making is a very long process and consists of many different chemical and mechanical process steps. The most important step of the whole leather making process is the tanning step, which is performed commonly either by vegetable or mineral tanning. More than $85-90 \%$ of the leather making is performed by chrome tanning, which is the most common type of mineral tanning currently applied.
\end{abstract}

Keywords: chrome tanning, greener technology, leather processing

\section{Introduction}

Tanning is the process of converting the raw skin and hides from different animals into a sustainable and manageable material called leather. Leather making is a very long process and consists of many different chemical and mechanical process steps [1]. The most important step of the whole leather making process is the tanning step, which is performed commonly either by vegetable or mineral tanning. More than $85-90 \%$ of the leather making is performed by chrome tanning, which is the most common type of mineral tanning currently applied $[2,3]$.

Chrome tanning is preferred by most tanners because chrome tanned leathers are characterized by top handling quality, high hydrothermal stability and excellent user properties in addition to the shorter time required to produce finished leather. Basically, it is very quick and easy to produce, usually only taking up to a day. In chrome tanning, final product is soft and supple to the touch and color remains the same throughout the products life. Moreover, it is cheaper to buy than vegetable tanned leather, which means it is also easier to find and having a high degree of thermal resistance. That's why it is economically suitable for leather tanning [4].

On the other hand, chrome tanning is the most polluting operation during the leather making process. The agents such as chromium can be highly toxic and polluting depending on its existing form. Chrome tanning is very bad for the environment and finish product contains often smells of chemicals. It doesn't wear very well or last long and can crack after a few months of use because of producing with little skill. In European countries, EU directives for leather industry have limited the use of chrome tanning which made it important to establish new techniques and strategies to ensure environmental protection [5].

\section{Nature of leather}

Leather is a natural durable and flexible material created by tanning animal rawhides and skins. The most common raw material is cattle hide. It can be produced at manufacturing scales ranging from artisan to modern industrial scale. Rawhides or skins undergo different type of mechanical and chemical technique including hair remove, trimming, soaking, liming, fat liquoring, tanning to produce finally durable and sustainable finish product of leather [6].

Leather consists of a three-dimensional network of collagen fibers. Its structure is quite different from that of textile fabrics in terms of fiber weave. The density of fiber assembly in leather shows an increasing gradient from flesh to grain layers, resulting in a difference in dye affinity between these two sides. In addition, the leather properties also vary due to differences in species, breed, living conditions of the animals. Different areas within the same hide or skin also have different properties. All these factors will affect tanning and the quality of tanned leathers. 


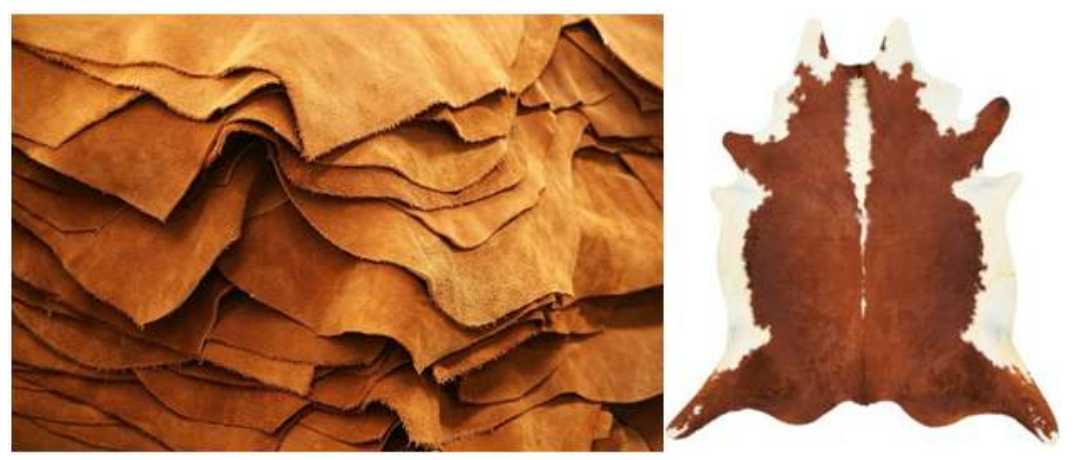

Figure 1 Nature and quality of leather

The quality and nature of leather depend on various factor such as type of hides (either bull hide or cow hide), Origin (Depends on health of animal), quality of rawhides, method of tanning either vegetable tanning or chrome tanning [7].

\section{Journey of Leather from primitive to versatile indus- try}

Leather has undoubtedly played a crucial part in the development of civilization. From early man to the modern day, leather has been an enduring feature of almost every era of design and fashion.

In the Paleolithic period, around 40,000 years ago, people started making moccasin-like wraparound footwear out of softened animal skins, or rawhide. This seemingly simple advancement gave humankind a major leg up in long-distance travel and marked the beginning of leather-making. When formerly nomadic tribes established agricultural settlements, animal husbandry provided a steady and easily accessible source of food and rawhide. This allowed our ancient ancestors to develop a process that made hides more durable and less susceptible to decomposition. This process evolved into the craft known as tanning [8].

Between 12,000 and 6,000 years ago, tanneries began cropping up in towns in Sumeria, Mehrgarh, and other ancient cultures. Due to its durability and comfort, leather has been used for seating throughout the history of transportation and furniture. It has always been the ideal material for making saddles and tack, as well as footwear. During the middle ages, leather became the cover of choice for dining chairs, because it was easy to maintain and did not absorb the odor of food [9].

The spread of industrialization in the 18th and 19th centuries created a demand for new kinds of leathers, such as belting leathers to drive machinery. The invention of the automobile, the demand for softer, lightweight footwear with a fashionable appearance, and a general rise in the standard of living created a demand for soft, supple, colorful leather. The traditional vegetable tanned leather was too hard and thick for these requirements and thus, the use of chromium salt was adopted and chrome tanning became the standard for modern footwear, fashion and upholstery leathers [10].

Modern technology has allowed for innovation in the leather industry, as the development of chemicals and sophisticated processing methods have greatly expanded the aesthetics and feel of leather as well as the possible applications. Leather continues to be the material of choice, not just for commercial and residential furniture but for automotive, aviation and marine applications as well [11].

\section{Tanning and its impact to leather processing}

Tanning is a chemical treatment process in which the soft and perishable proteins of animal hides or skins are converted into durable and flexible leather. In vegetable tanning, the active agent is tannic acid derived from the bark of certain trees. In chrome tanning, salts of metals such as aluminum, chromium, and zirconium are used. Also called curing. Tanning hide into leather involves a process which permanently alters the protein structure of skin, making it more durable and less susceptible to decomposition, and also possibly coloring it [12]. 
Before tanning, the skins are epilated, degreased, desalted and soaked in water over a period of 6 hours to 2 days. Historically this process was considered a noxious or "odoriferous trade" and relegated to the outskirts of town. Traditionally, tanning used tannin, an acidic chemical compound from which the tanning process draws its name (tannin is in turn named after an old German word for oak or fir trees, from which the compound was derived). The use of a chromium (III) solution was adopted by tanners in the Industrial Revolution [13]. In olden times, tanning was considered to be an 'odoriferous' trade. Tanning by ancient methods was indeed extremely foul- smelling and hence most tanneries were situated in the outskirts of towns. The use of urine and animal faces, combined with the smell of decaying flesh due to the absence of conservation options was what made ancient tanneries so odoriferous and the profession of tanner unpopular [14].

Proper tanning is the most important step in leather production. It is just one part in the entire process of manufacturing leather. Tanning is the method of preserving animal skin, with or without hair using tannins. These are acidic chemical compounds that stabilize the fiber structure of the skin and prevent it from decaying, decomposing and oxidizing. A tannery is where these skins and hides are processed and the profession is called tanner. The tanning process involves many stages where the skins have to be treated first and, once tanned, depending on the application and specific customer requests, the leather is dyed, ironed, sanded, oiled etc. There are endless variations [15].

\subsection{Purpose of tanning leather}

(1) The skin is made up of one third protein (collagen). Tannins preserve the flexibility of these protein strands and the entire tanning process prevents the protein filaments from hardening and becoming tacky on drying. 'Parchment' is not tanned and hence different to leather. It is hard and translucent.

(2) Tanning makes the leather resistant to decay (self-decomposition by microorganisms).

(3) The swelling of the fibers on wet leather is prevented.

(4) Temperature resistance is significantly increased. Untanned skin shrinks in water at $62^{\circ} \mathrm{C}$. Chrome-tanned leather is resistant up to $100^{\circ} \mathrm{C}$. The fibers do not stick to each other and the leather does not shrink [16].

\section{Chrome tanning and its benefits}

When the Leather is tanned by chrome powder then the process is called chrome tanning \& material called chrome tanning. The use of chromium (III) salts is currently the commonest method of tanning. In the following decades, chrome tanning became the most common and dominant form of tanning. One of the main reasons why it was adopted so rapidly is that the process was much faster than vegetable tanning. The invention of chrome tanning coincided with the discovery of the fat liquoring (regressing) process and also the development of synthetic dyes. Together these changes to the chemistry of leather production led to chrome tanning becoming the preferred method. Chromium salts belong to the group of mineral tannins. Immediately after tanning, the leather is still wet and is tinged with blue, hence it is also referred to as wet blue [17].
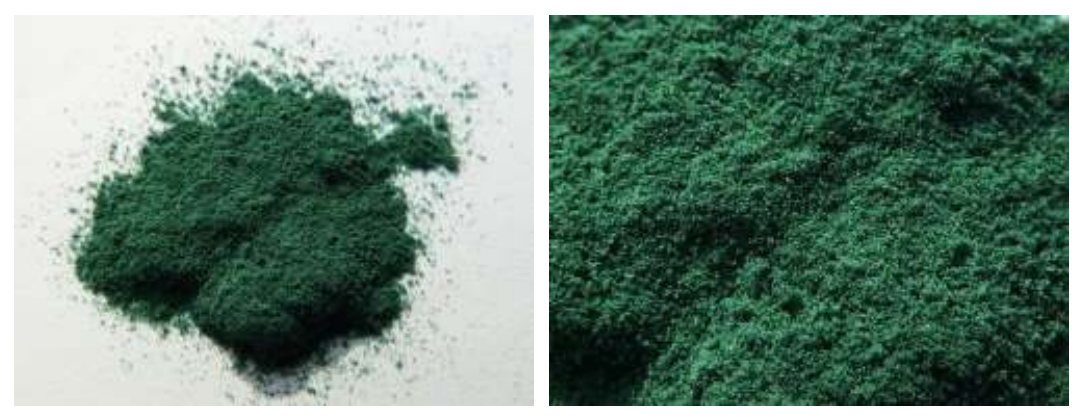

Chromium (III) oxide in powder form.

Chrome tanning with chromium (III) salts accounts for around 85 percent of global leather production (as per 2014). 95\% of shoe upper leather, $70 \%$ of leather upholstery (but decreasing in favour of FOC-leather) and almost 100\% of clothing leather are chrome tanned. Although it has twice the tensile strength of vegetable tanned leather, chrome-tanned leather weighs less because 
the skin does not fully absorb the chromium salts used for tanning. The tannin makes up just $4 \%$ (with newer leathers only about $1.5 \%$ ) of the leather weight, while vegetable-tanned leather has a tannin content of about $20 \%$. Chrome-tanned leather is more easily hydrophobized compared to other tanning alternatives and the leather can be softened more easily. The tanning process is faster and requires less tanning chemistry than vegetable-tanned leather. Freshly tanned wet blue with its characteristic bluish tin is globally transportable and can be stored well. This facilitates unlimited international sales and global processing [18].

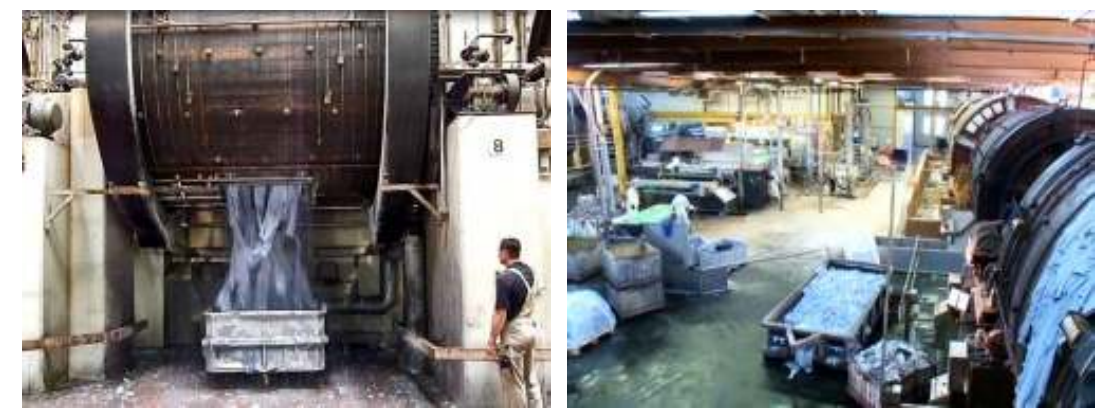

Figure 2 Chrome tanning in the tanning drum

Table 1 Proportion of chrome-tanned leather in various sectors of use [19]

\begin{tabular}{lcl}
\hline Area & Chrome-tanned leather in $\%$ & Tendency \\
\hline Shoe upper leather & 95 & No change \\
Furniture leather & 70 & Decrease in favor FOC-leather) \\
Car leather & 50 & Decrease in favor FOC-leather) \\
Garment leather & 100 & No change \\
Bags, belts, accessories & 60 & No change \\
Sole leather & - & No change \\
\hline
\end{tabular}

The chrome-tanning agent nearly always contains $33 \%$ basic chromium sulfate and $26 \%$ chromium (III) oxide. Annually 480,000 tons are produced in chrome tanning worldwide, which is about 125,000 tons of chromium (III) oxide. The use of chromium (III) salts is considered harmless to health and does not cause difficulties in the vast majority of people, despite intensive skin contact in footwear or apparel. Drinking water is allowed to contain 50 micrograms (chromium III) per liter. Major suppliers of chromium are South Africa with 38\%, India 20\%, Kazakhstan 15\%, Turkey with 7\%, Russia, Brazil and Zimbabwe each with 3\% and Finland with $2 \%$ [20].

\section{Chrome tanning and its relation with environment problem}

The main threat to the environment results from the dumping of liquid and solid waste that contains leftover chromium. In some commercial operations $50 \%$ of the chromium used in the tanning process is finding its way into the local environment. The run off and scraps are then consumed by animals and subsequently by humans: $25 \%$ of the chickens in Bangladesh were found to contain harmful levels of hexavalent chromium [21].

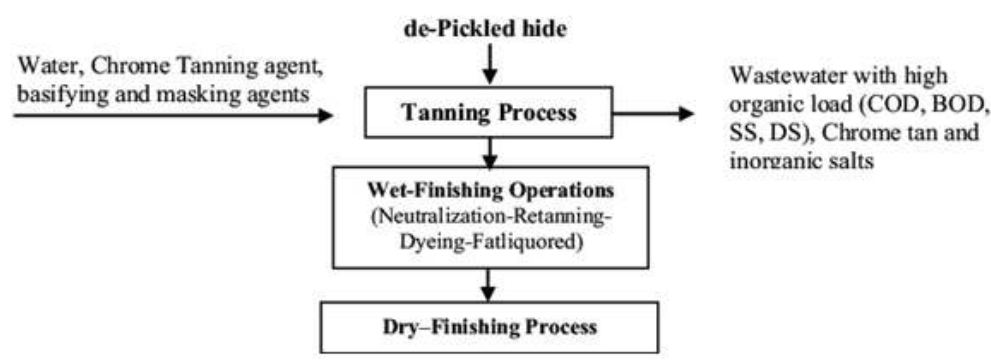

Figure 3 Schematic diagram of the environmental impact associated with tanning process 
In addition to creating potentially toxic wastewater, some tanneries also produce large amounts of solid waste that contain chromium, including: hide scraps, skins, and excess fats. Toxins from this waste can leach into nearby soil and water, placing nearby residents at risk of contamination.

A large portion of the world's tanning industry operates in low- and middle-income countries, and the percentage of these countries contributing to light and heavy leather materials increased from $35 \%$ to $56 \%$ and $26 \%$ to $56 \%$, respectively, between 1970 and 1995 . Many of these tannery sites are clustered together, creating heavily polluting industrial areas in many countries In Hazaribagh, for example - a particularly large tanning region of Bangladesh that has over 200 separate tanneries-it is estimated that 7.7 million liters of wastewater and 88 million tons of solid waste are disposed of on an annually. These pollutants are responsible for the contamination of all nearby surface and groundwater systems with severely high levels of chromium [22].

\section{Effect of chromium in human health}

When chromium enters the water system in large quantities it can cause respiratory problems, infertility and birth defects. The use of chromium also puts workers at risk during the tanning process. If the dust, which is produced when chrome tanned leather is buffed or ground up, is inhaled, it can cause respiratory problems and increase the risk of lung cancer. When chromium comes in contact with the skin it causes dryness and cracking and sores, known as "chrome holes'. An important health risk factor for the tannery workers is occupational exposure to chromium, which is used as a basic tanning pigment. The workers on exposure to leather dust, which contains chromium in the protein-bound form, exhibited a higher mean concentration of urinary and blood chromium than the reference values. The personal sampling conducted at different work sites exhibited higher levels of total chromium. The high morbidity $(40.1 \%)$ observed in the tanners in comparison to the reference values (19.6\%) could be due to high levels of chromium in the biological samples of the exposed workers and air samples collected at the worksite. The increased morbidity in the exposed workers could be attributed to high respiratory illness (16.7\%) compared with $4.27 \%$ in the control group [23].

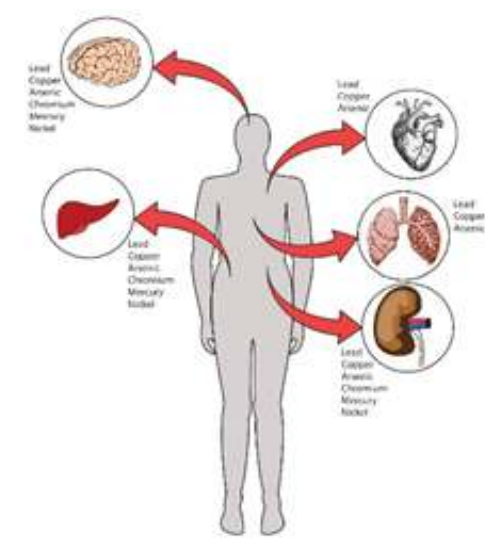

Figure 4 Effect of heavy metal as chromium in human health

The higher biological values of chromium among the tanners could be explained by atmospheric pollution caused by the liberated leather dust at the work place. The increased pulmonary morbidity is also associated with certain characteristic symptoms such as dry cough $(5.6 \%)$, throat irritation (3.6\%) and lung congestion in 3.0\% of the workers. The hexavalent chromium is rapidly absorbed by the lungs into the blood and easily penetrates the cellular membranes and binds to the hemoglobin in the red blood cells thereby affecting the oxygen carrying capacity and impairing the lung function status. Even chrome tanned leather in its finished form poses an environmental threat: if the leather seats from scrapped cars are burnt then toxic chromium V1 may be released into the atmosphere. This can even occur as a result of car upholstery being exposed to prolonged strong sunlight. New, 'green technologies' do hold out the prospect of converting toxic waste into useful products and purifying and recycling contaminated waste water, however it is unlikely that in poorer countries, where the bulk of chrome tanning takes place, there will be an investment in costly alternative 'green technology' [24]. 


\section{Possible remedy of environment and human health problem by replacing chrome tanning by vegetable tanning}

Chrome tanning are highly risk for human health and our environment especially, Chromium from leather tanning can make its way into air, soil, food, and water, and the most common forms of exposure are through inhalation of dust or fumes and ingestion of or contact with contaminated water. To get rid of this effects, possible remedy of environment and human health problem may be considered vegetable tanning process. Various new ways of tanning leather have been used which is eco-friendly, vegetable tanning is one of them. Vegetable tanning uses tannins (a class of polyphenol astringent chemicals), which occur naturally in the bark and leaves of many plants. Tannins bind to the collagen proteins in the hide and coat them, causing them to become less water-soluble and more resistant to bacterial attack. The process also causes the hide to become more flexible. The primary barks processed in bark mills and used in modern times are chestnut, oak, redoul, tanoak, hemlock, quebracho, mangrove, wattle (acacia; see catechol), and myrobalans from Terminalia spp., such as Terminalia chebula [25].

There are many benefits to vegetable tanning. First, it is a healthier process for the worker, as no chemicals are used. Therefore, it's not dangerous for him. This method is less harmful to our Earth and more environmentally friendly because the tannin comes from the nature. It's better for the health of users because of safety and hypoallergenic qualities. Unlike chromium, which is well-known for causing many allergies. In addition, the vegetable tanned leather offers stiffer, firmer and stronger leather. It has a good holding and a better moisture absorption. It also has natural colors and so we can get deeper and more nuanced shades. It has the advantage of aging well and to embellish over the years with a nice patina. Vegetable tanned leather is always appreciated for its looks, it is touch and its natural smell. There are other ways to make leather but none offer the rich aroma that vegetable tannins give to the hides and skins. Most vegetable tanned leathers have just a waxed, oiled or polished surface and the natural grain surface of the leather, shaped originally by the pattern of the hair or wool remains visible. This makes vegetable tanned leather, or at the minimum vegetable re-tanned leather, the preferred choice for tablet and phone covers. Humanizing the modern world of gadgets yet offering what is needed for exquisite contemporary design. Vegetable tanned leather is perfect for craftsmanship because of this ability to accept molding, embossing and inks. Various finishes can be put on the leather according to end uses.

All in all, you should adopt vegetable tanned leather to preserve the manufacturer and user health, the environment, as well as for its qualities as a sustainable material [26].

\section{Use of ultrasound in eco-friendly chrome tanning}

Tanning is one of the most time consuming processes in leather making. Therefore, a considerable number of new techniques have been studied which offer to speed up the process without impairing the quality of the finished product.

Ultrasound is a sound wave with a frequency above the human audible range of $16 \mathrm{kHz}$. Ultrasound having a frequency range of $20-100 \mathrm{kHz}$ is commonly employed for enhancing the physical processes such as cleaning, emulsification, degassing, crystallization, extraction, etc., and for performing chemical reactions. Ultrasound is a high frequency sound wave which can be transmitted through any elastic medium [27]. In a liquid medium the oscillation of the molecules induced by the sound wave generates cavitation bubbles throughout the system. The collapse of these bubbles in an acoustic field generates a highly localized region of extremely high temperature, pressure and shear force. In the present paper, the use of US in the conventional chrome tanning process has been studied at different $\mathrm{pH}$, temperature, tanning time, chrome dose and US exposure time by exposing the skin before tanning and during tanning operation. Both prior exposure of the skin to US and US during tanning improves the chrome uptake and reduces the shrinkage significantly. Prior exposure of the skin to US increase the chrome uptake by $13.8 \%$ or reduces the chrome dose from $8 \%$ to $5 \%$ (\% based on skin weight) and shorten the process time by half while US during tanning increases the chrome uptake by $28.5 \%$ or reduces the chrome dose from $8 \%$ to $4 \%$ (half) and the tanning time to one third compared to the control without US. Concomitantly, the resulting leather quality (measured as skin shrinkage) improved from $5.2 \%$ to $3.2 \%$ shrinkage in the skin exposed to US prior tanning and to $1.3 \%$ in the skin exposed to US during the tanning experiment. This study confirms that US chrome tanning is an effective and eco-friendly tanning process which can produce a better quality leather product in 
a shorter process time with a lower chromium dose. The potential use of ultrasound in process industries such as leather, chemical and textiles with the aim to reduce process time, pollution load and to get improvement in the product quality are being studied extensively [28].

Therefore, the application of power ultrasound within the leather industry will accelerate most of the wet processes by enhancing the diffusion and penetration of tannin into the leather and by increasing the interaction between tannin and leather fibers. The aggregation of tanning materials was reduced by ultrasound, while the high speed of the moving wave may also help the tannin penetrate inside the leather [29].

\section{Waste management of chrome tanning}

Tannery wastewaters are highly complex and are characterized by high contents of organic, inorganic and nitrogenous compounds, chromium, sulfides, suspended solids and dissolved solids. In general, tannery wastewaters are basic, have a dark brown color and have a high content of organic substances that vary according to the chemicals used. The influents were characterized by high alkalinity content with a resulting $\mathrm{pH}$ value of above 8 due to the chemicals used in leather processing [30]. Treatment of sludge constitutes the largest disposal problem, apart from effluent. Sludge of organic composition, if free from chrome or sulfide, have value as a soil conditioner as well as a small fertilizer effect from nitrogenous compounds contained therein. These benefits are best realized by ploughed immediately after application. Agricultural use of chrome-containing soils has been a matter of controversy in various jurisdictions, where guidelines have determined acceptable applications. Various markets exist for the conversion of trimmings and fleshing into by-products used for a variety of purposes, including the production of gelatin, glue, leather board, tallow grease and proteins for animal feed. Process effluents, subject to suitable treatment and quality control, are sometimes used for irrigation where water is in short supply or effluent disposal is severely restricted. To avoid problems of leachate generation and odor, only solids and dewatered sludge should be disposed of at landfill sites. Care must be taken to ensure that tannery wastes do not react with other industrial residues, such as acidic wastes, which can react to create toxic hydrogen sulfide gas. Incineration under uncontrolled conditions may lead to unacceptable emissions and is not recommended [31]

\section{Pollution Prevention}

Improving production technologies to increase environmental performance can achieve a number of objectives, such as:

(1) Increasing the efficiency of chemical utilization;

(2) Reducing water or energy consumption;

(3) Recovering or recycling rejected materials.

Water consumption can vary considerably, ranging from less than $251 / \mathrm{kg}$ of raw hide to greater than 80 1/kg. Water use efficiency can be improved through the application of techniques such as increased volume control of processing waters, _ batch versus _ running water washes, low float modification of existing equipment; low float techniques using updated equipment, re-use of wastewater in less critical processes and recycling of individual process liquors [32] Traditional soaking and epilate account for over $50 \%$ of the BOD and chemical oxygen demand (COD) loads in typical tanning effluents. Various methods can be employed to substitute for sulfide, to recycle lime/sulfide liquors and to incorporate hair-saving techniques. Reduction in chromium pollution can be achieved through measures to increase the levels of chrome that are fixed in the tanning bath and reduce the amounts that are _ bled out in subsequent processes. Other methods to reduce release of chromium are through direct recycling of used chrome liquors (which also reduces salinity of waste effluent) and the treatment of collected chrome-bearing liquors with alkali to precipitate the chromium as hydroxide, which can then be recycled [33].

\section{Conclusion}

Almost all tanneries use chrome tanning process to make good quality leather. These chromium salts and its derivatives are very perilous to human health and to the environment. The outcome of the research work clearly suggests that chrome tanning system can be replaced by vegetable tanning system so that the perilous environmental impacts caused by the chromium compounds can be eliminated. Moreover, Ultrasound technique can be used to speed up the rate 
of both chrome and vegetable tanning to reduce the harmful impact of environment and human health. Although chrome tanning has several benefits over other vegetable tanning, especially production time and cost, it has negative impacts to human health and environment.

\section{References}

[1] Parivallal B and Ramanujam R. Studies on degradation of suntan used in leather tanning process using ozone. International Journal of Environmental Science and Development, 2010, 53: 264-267. https://doi.org/10.7763/IJESD.2010.V1.51

[2] Krishnamoorthy G, Sadulla S, Sehgal P, et al. Greener approach to leather tanning process: d-Lysine aldehyde as novel tanning agent for chrome-free tanning. Journal of Cleaner Production, 2013, 42: 277-286. https://doi.org/10.1016/j.jclepro.2012.11.004

[3] Theis E and Goetz A. Chrome Tanning I. The role played by sodium chloride in chrome liquors upon chrome tanning. Industrial \& Engineering Chemistry, 1932, 24(3): 304-307. https://doi.org/10.1021/ie50267a009

[4] Nashy E and Eid K. Reduction of chrome tanning effluent impact and enhancement of leather properties based on high exhaustion of chrome tan. Egyptian Journal of Chemistry, 2018, 5: 12-18. https://doi.org/10.21608/ejchem.2018.4393.1387

[5] Puccini M and Castiello D. Use of glucose to improve the environmental aspects of chrome tanning trocess. Advanced Materials Research, 2014, 933: 144-150. https://doi.org/10.4028/www.scientific.net/AMR.933.144

[6] Gondim R, Marinho R and Conceição R. Tanning handmade leather tilapia (oreochomis sp.) from three natural tanning. Revista Brasileira de Higiene e Sanidade Animal, 2015, 9(2): 172-184. https://doi.org/10.5935/1981-2965.20150016

[7] Sakmat J, Lopattananon N and Kaesaman A. Effect of fiber surface modification on properties of artificial leather from leather fiber filled natural rubber composites. Key Engineering Materials, 2015, 659: $378-382$. https://doi.org/10.4028/www.scientific.net/KEM.659.378

[8] Das S. Animal husbandry practices of livestock keepers in mizoram: a case study. International Journal of Bio-resource and Stress Management, 2018, 9(5): 580-584. https://doi.org/10.23910/IJBSM/2018.9.5.1900

[9] Maria J. Festive meals in the late middle ages. An essay on dining as a means of communication Food and History, 2003, 1: 95-102. https://doi.org/10.1484/J.FOOD.2.300505

[10] Snooks G. A general theory of complex living systems: Exploring the demand side of dynamics. Complexity, 2008, 13(6): 12-20. https://doi.org/10.1002/cplx.20225

[11] Jhonson R. Sealing material for automotive applications. Sealing Technology, 2018, 5: 13-21. https://doi.org/10.1016/S1350-4789(18)30221-6

[12] Theis E and Goetz A. Chrome Tanning I. The role played by sodium chloride in chrome liquors upon chrome tanning. Industrial \& Engineering Chemistry, 1932, 24(3): 304-307. https://doi.org/10.1021/ie50267a009

[13] Wilson $\mathbf{J}$ and Kern E. Nature of the hide-tannin compound and its bearing upon tannin analysis. Journal of Industrial \& Engineering Chemistry, 1920, 12(12): 1149-1151. https://doi.org/10.1021/ie50132a008

[14] Qin A and Kalemkerian G. Treatment options for relapsed small-cell lung cancer: What progress have we made?. Journal of Oncology Practice, 2018, 14(6): 369-370. https://doi.org/10.1200/JOP.18.00278

[15] El-Khateeb M, Nashy E, Ghany N, et al. Environmental impact elimination of chrome tanning effluent using electrocoagulation process assisted by chemical oxidation. Desalination and Water Treatment, 2017, 65: 147-152. https://doi.org/10.5004/dwt.2017.20250

[16] Kasim A, Novia D, Mutiar S, et al. Diminishing chromium use on combined chromium-gambier tanning process upon the characteristics of tanned leather. Media Peternakan, 2014, 37(1): 24-29. https://doi.org/10.5398/medpet.2014.37.1.24

[17] Suresh V, Kanthimathi M, Thanikaivelan P, et al. An improved product-process for cleaner chrome tanning in leather processing. Journal of Cleaner Production, 2001, 9(6): 483-491. https://doi.org/10.1016/S0959-6526(01)00007-5

[18] Bowker R and Emley W. Comparative wear of chrome-tanned, vegetable-tanned, and retanned sole leather. Journal of Research of the National Bureau of Standards, 1935, 15(4): 363-368. https://doi.org/10.6028/jres.015.022

[19] Ebrahiem M, Turki I and Haroun H. The effect of breed on skin/leather quality of sudan desert sheep. Journal of Africa Leather and Leather Producuts Advances, 2014, 1(1): 45-53. https://doi.org/10.15677/jallpa.2014.v1i1.5

[20] Vasović D and Stojaković D. Preparation of chromium(III) phthalate and chromium(III) pyromellitate via chromium(VI) oxide. Journal of Coordination Chemistry, 1992, 25(3): 221-227. https://doi.org/10.1080/00958979209409194 
[21] Ellis A. Chromium isotopes and the fate of hexavalent chromium in the environment. Science, 2002, 295(5562): 2060-2062.

https://doi.org/10.1126/science. 1068368

[22] Abdel-Shafy H, Hegemann W and Genschow E. Fate of heavy metals in the leather tanning industrial wastewater using an anaerobic process. Environmental Management and Health, 1995, 6(2): 28-33. https://doi.org/10.1108/09566169510085135

[23] Kasim A, Novia D, Mutiar S, et al. Diminishing chromium use on combined chromium-gambier tanning process upon the characteristics of tanned leather. Media Peternakan, 2014, 37(1): 24-29. https://doi.org/10.5398/medpet.2014.37.1.24

[24] Tremper K. Hemoglobin-based oxygen carrying solutions: Will they replace red blood cells?. Anesthesia \& Analgesia, 2005, 100(4): 910-911. https://doi.org/10.1213/01.ANE.0000149596.56181.75

[25] Srivastava S and Srivastava S. New biologically active constituents from Terminalia Chebula stem bark. ChemInform, 2005, 36(17): 2731-2733. https://doi.org/10.1002/chin.200517197

[26] Udkhiyati $M$ and Silvianti $F$. The utilization of chitosan as natural antibacterial for vegetable tanned leather. Materials Science Forum, 2019, 948: 212-216. https://doi.org/10.4028/www.scientific.net/MSF.948.212

[27] Simić M. Complex impedance measurement system for the frequency range from $5 \mathrm{kHz}$ to $100 \mathrm{kHz}$. Key Engineering Materials, 2015, 644: 133-136. https://doi.org/10.4028/www.scientific.net/KEM.644.133

[28] Theis E and Goetz A. Chrome tanning I. The role played by sodium chloride in chrome liquors upon chrome tanning. Industrial \& Engineering Chemistry, 1932, 24(3): 304-307. https://doi.org/10.1021/ie50267a009

[29] Teng B, Jian X and Chen W. Effect of thallic acid content on tannin-titanium (III) combination tanning. Leather and Footwear Journal, 2013, 13(1): 3-12. https://doi.org/10.24264/lfj.13.1.1

[30] Liu S, Tong X and Song B. A compact and efficient technology to treat tailings water characterized by high alkalinity and $\mathrm{Ca}$ (II) and $\mathrm{Pb}$ (II) concentration. Advanced Materials Research, 2012, 518-523: 2278-2282. https://doi.org/10.4028/www.scientific.net/AMR.518-523.2278

[31] Madera C, Peña M and Mara D. Microbiological quality of a waste stabilization pond effluent used for restricted irrigation in Valle Del Cauca, Colombia. Water Science and Technology, 2002, 45(1): $139-143$. https://doi.org/10.2166/wst.2002.0019

[32] Fox K. Water treatment and equipment decontamination techniques. Journal of Contemporary Water Research \& Education, 2009, 129(1): 18-21. https://doi.org/10.1111/j.1936-704X.2004.mp129001005.x

[33] Gustavson K. Fixation of constituents of chrome liquors by hide substance from highly concentrated chrome solutions. Industrial \& Engineering Chemistry, 1925, 17(8): 823-826. https://doi.org/10.1021/ie50188a018 